\title{
REPORT OF A CASE OF TRANSITIONAL PSYCHOSIS.'
}

BY F. SAVARY PEARCE,

of Philadeiphia.

$\mathrm{O}^{\mathrm{N}}$

$\mathrm{N}$ Aug. 20, 1895, a slightly built man, thirty-three years of age, with light hair and that peculiar physiognomy which at once suggested the "crank" reported to the Medical Clinic at St. Agnes Hospital, with the statement that he was suffering from a tapeworm. He gave his name John J. R., and was an American. The following record was then made:

Family History.-Mother died of phthisis. Father died of dropsy. No neurotic history or any information of value could be obtained as to his ancestry.

Previous History.-Has always been a person of very slight build and did not remember of having had any very serious ailment. He has always been a great smoker. Alcoholism and syphilis are denied. The first note bearing on his present mental condition reads as follows: Some years ago, he joined a "swindling scheme" and indulged in pocket picking, for which offense he served a sentence in the Eastern Penitentiary.

In I 889 he said he began to have "fits," which would come on at night. He never bit his tongue in any of these fits, but he affirms unconsciousness during them, and there is reason to lead us to suspect that they were epileptiform; possibly hystero-epilepsy. These spells were quite frequent until i 893. Then they became even more frequent; about once. a month. His last fit was only six weeks ago. There is never any aura to warn him of an attack. Since the spells have become more frequent (in '93) he say's he has "become confused" in his head. He persists that now the confusion is more due to a tapeworm, which for some time and at.present is drawing "brain matter" from his head. This brain matter, he thinks, is returned again. He has linked with the delusion of tapeworm the idea of having "in-

\footnotetext{
${ }^{1}$ Read at the meeting of the Philadelphia Neurological Society, Nov. 25, 1895 .
} 
haled" into his stomach some steel filings or dust, which is doing him bodily harm. The sexual desire has been lost, which he also imagines is due to taking cod liver oil; but thinks the oil is doing him enough good otherwise to make up for this latter loss. He has been taking the cod liver oil to "oil his lungs," and firmly believes that he is absorbing some deleterious material from his lungs thereby.

As far as I could make out he has nodelusions of persecution, but rather tends to that of grandeur. The cgo is prominent.

He believes that John the Baptist is about to come to reform the world, and that he will turn out to be the man, but we could obtain no fixed ideas or paranoiacal reasonings as to why or how he was to accomplish the task. He had been the rounds of the hospitals, and was anxious to move on to another one before the pliysical examination was finished. This was a man of small type, light hair, stoop shoulders, expression of mental instability, muscular development fair for his size. Head is well formed, ears not badly set and of good shape. Station is good, with eyes closed and heels placed together. Tongue is protruded straight. Teeth are somewhat decayed, and are not abnormal as to shape or position. Hard palate well formed. Knee-jerks and other reflexes normal. There are no areas of anaesthesia, and no motor paresis can be found. There is a marked antero spinal curve at the sixth dorsal vertebra, but no signs of kyphosis from Pott's disease. The chest expansion is good. Heart sounds rythmic, no murmur. No evidences of abdominal disease exist.

It was with difficulty that the interne, Dr. Greenleaf, could detain the man after clinic hour long enough to complete the foregoing history, and the patient became for the first time excited when his cunningness revealed to him that his compos mentis was, perhaps, being questioned.

We were unable to have him return again, since, at the terminus of the examination he was quite sure he understood his own case better than any doctors.

In seeking more information about the patient we consulted Dr. Ball, who did not remember the case, and Dr. John Bacon, now physician to the Eastern Penitentiary, writes that John R. was a prisoner there in the eighties, and there is no note of his mental status. The man may have given an assumed name, but from his 
statements as to his surroundings there, one cannot doubt of his penal incarceration.

Here, then, seems to be a case that is a born moral pervert, a person witha congenitally degenerate brain, who in youth begins swindling and the like, is imprisoned for pocket-picking without any signs of remorse; who finally shades off into an additional aspect of his loss of mental balance (i. e., epileptoid seizures) and now, as the most prominent aberration in the case, he has verged off from a "hyped" individual to an, as yet, inoffensive delusional form of insanity; no delusions of persecution or homicidal tendencies being evident. This transition from impulses to swindle, steal, etc., in youth, to the added convulsive psychosis, and then to a marked delusional state of morbidity, is manifestly, stages only in the mental astigmatism of the unfortunate individual. The question arises as to ones ${ }^{2}$ duty in such a case more and more as the study of mental disease advances, and as the newspaper records of instances of sudden or premeditated violence and homicides are brought to public attention.

How soon a man like this one may not assume the title rôle of the duality and become the "John the Baptist" he speaks of, with the radical idea of killing some one of state to "reform the world" it would be difficult to surmise. Under present laws no physician would probably be sustained by the courts in an effort at forcible incarceration.

The complex subject as to commitment here has a gravity to it pro and con, which constantly increasing unfortunate statics can alone bring to a right decision.

The timely paper of Dr. Theodore Diller, ${ }^{2}$ read before the Allegheny County Medical Society, brings the matter up in its true light forcibly before the people.

Whether the incendiary work of such so-called cranks, together with the bad moral influence upon a community, and the murders occasionally committed by them, would balance the scales with the financial outlay of the government necessary to maintain an institution for their charge is still an open question.

1407 Locust Street.

"What shall be done with the "Homicidal Crank?" Philadelphia Polycinic, Aug. 1o and 17,1895 . 